\title{
GOVERNANÇAS COOPERATIVAS SUSTENTÁVEIS NA GESTÃO METROPOLITANA FLUMINENSE: DESAFIOS GEOGRÁFICOS \\ SUSTAINABLE COOPERATIVE GOVERNANCE IN FLUMENAN METROPOLITAN MANAGEMENT: GEOGRAPHICAL CHALLENGES
}

\author{
Augusto César Pinheiro da Silva' \\ ${ }^{1}$ Pontifícia Universidade Católica do Rio de Janeiro (PUC-Rio), Rio de Janeiro, RJ, Brasil \\ Correspondência para: Augusto César Pinheiro da Silva (augustoc@puc-rio.br) \\ doi: 10.12957/geouerj.2017.32065 \\ Recebido em: 1 nov. 2017 | Aceito em: 12 dez. 2017
}

\section{RESUMO}

Os estudos sobre os modelos de governança cooperativa em ambientes metropolitanos vêm sendo ampliados no Brasil, atualmente, devido às configurações territoriais e demográficas que se formam no espaço nacional. Tais configurações afetam a qualidade da gestão dos territórios instituídos no país, desafiando a sociedade a reordenar as funções e os papéis metropolitanos na esfera política brasileira. Nesse sentido, os centros de pesquisa em Geografia política retomam as discussões realizadas por juristas, cientistas sociais e técnicos sobre os problemas institucionais da cooperação interinstitucional na escala das metrópoles brasileiras, cujos serviços públicos são competitivos entre si. Tal competição afeta a qualidade de vida de milhões de pessoas nas metrópoles, sendo o caso da Região Metropolitana do Rio de Janeiro emblemático para o estudo das funções metropolitanas dos serviços essenciais na cultura federalista brasileira.

Palavras-chave: Governança. Federalismo. Gestão do território. Geografia do Rio de Janeiro. Funções metropolitanas.

\begin{abstract}
Studies on the models of cooperative governance in metropolitan environments have been expanded in Brazil, currently, due to the territorial and demographic configurations that are formed in the national space. Such configurations affect the quality of the management of the territories established in the country, challenging the society to reorder the functions and the metropolitan roles in the Brazilian political sphere. In this sense, the research centers in Political Geography retake the discussions carried out by jurists, social scientists and technicians on the institutional problems of interinstitutional cooperation in the scale of the Brazilian metropolises, whose public services are competitive among themselves. Such competition affects the quality of life of millions of people in the metropolis, being the case of the Metropolitan Region of Rio de Janeiro emblematic for the study of the metropolitan functions of essential services in Brazilian federalist culture.
\end{abstract}

Keywords: Governance. Federalism. Territory management. Geography of Rio de Janeiro. Metropolitan functions.

\section{APRESENTAÇÃO}

As configurações territoriais e suas representações políticas, na atualidade, estão em plena metamorfose. A comprovação de que os modelos instituídos para a representação espacial nas esferas 
decisórias do modelo federal brasileiro precisam de ajustes sistêmicos é inegável frente aos eventos sociopolíticos ${ }^{1}$ nos diversos fragmentos espaciais no país, no tempo presente.

Dentre os ajustes sistêmicos urgentes e fundamentais para as próximas décadas, os graus e intensidades de competências entre os agentes de representação e suas solidariedades intersetoriais, a emergência de novas formas de governança que atendam as demandas espaciais fundamentadas em desejos coletivos mais amplos/restritos de variados grupos sociais e novas arquiteturas políticoinstitucionais de gestão dos territórios sob o manto legal de outra legislação factível de solidariedades e coparticipações nas esferas da política e da sociedade territorializada merecem destaque, pois reflexões mais constantes sobre esses ajustes demandam redes de ação acadêmica, social e política mais constantes e frequentes.

Tais solidariedades, aqui entendidas no sentido concebido por Silva (2002) ao tratar a cooperativização ${ }^{2}$ entre instituições privadas e públicas como uma 'luta não corporativa entre atores e agentes diversos por qualidade de vida em um mundo desigual', reforçam as discussões sobre o modelo federativo brasileiro e suas formas de representação político-institucional. Tal modelo, já indicado por pesquisadores como Souza (2005, 2008, 2017), Castro (2005, 2006) e Rodrigues (2015) como pouco adequado aos padrões de qualidade exigidos para a gestão das coisas públicas, necessita de urgente revisão de concepção e legislação na inadequada Carta Magna brasileira, que não reflete o perfil socioespacial atual do país.

\footnotetext{
${ }^{1}$ Os eventos sociopolíticos expressivos nos últimos quatro anos (2013-2017) destacados são: as manifestações de rua de 2013, a reeleição (2014) do Governo federal em uma relação de clara divisão (52\% X 48\%) entre os formadores de opinião do país e o decorrente acirramento das tensões políticas e ideológicas na atualidade, o impeachment desse mesmo Governo federal eleito, entre 2015 e 2016, por uma sociedade esgarçada, a crise do poder Judiciário no país, com a luta entre os legisladores e juízes desde o advento da Operação Lava Jato, em março de 2014, a recessão da economia brasileira que retrocedeu o país às condições de qualidade de vida de quase duas décadas passadas, a crise de legitimidade das eleições municipais e estaduais brasileiras, em 2016, quando os votos brancos e nulos atingiram o patamar histórico de $33 \%$ do total e as delações premiadas, que vêm atingindo as representações em todas as escalas do poder público.

${ }^{2}$ Processo que expressa a Teoria de Münster, uma dimensão mais adequada, a partir dos anos de 1980, de uma coparticipação competitiva e cooperativa entre atores e agentes que expressam a cooperação para muito além dos pressupostos clássicos de Rochedale (século XVIII), conectando-se o conceito de cooperativização aos tempos atuais de globalização e das sociedades em rede e atomizadas.
} 
No caso das regiões metropolitanas brasileiras que, em alguns casos, incorporam o sentido de megarregião na concepção de Lencioni (2015), a organização espacial altamente densificada concentra poder econômico e político e, ao mesmo tempo, possui um apelo cultural e social arraigado por agregar funções de core areas. Todavia, em muitos casos (e cada vez mais frequente), tal condição de poder reverte-se negativamente em relação ao que se esperaria de 'espaços repletos de potencialidades', já que em ambientes altamente urbanizados convergem padrões atuais de qualidade de vida ${ }^{3}$ (perspectivas holísticas com outras que tomam formas de concretude material no cotidiano territorial), que, em condições de grande desigualdade socioespacial, geram um grande mal estar coletivo e individual.

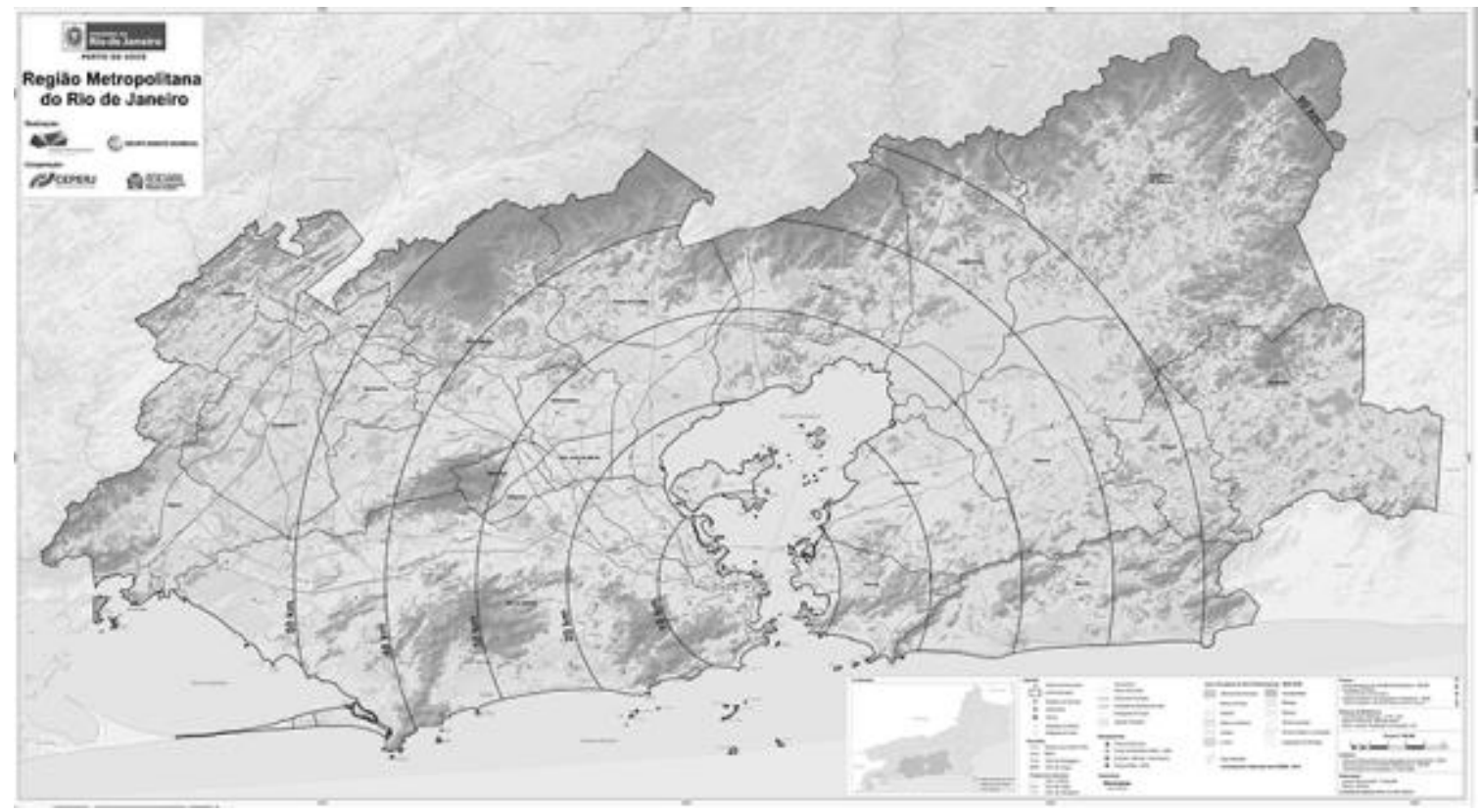

Mapa 1. Região Metropolitana do Rio de Janeiro (RMRJ), em 2017. FONTE: Adaptado do site http://www.modelarametropole.com.br/documentos/. Acesso: 12 jul. 2017.

\footnotetext{
${ }^{3}$ Em uma tentativa de análise da qualidade de vida de forma mais ampla, saindo principalmente do reducionismo biomédico, autores diversos abordam essa concepção como uma representação social criada a partir de parâmetros subjetivos (bem estar, felicidade, amor, prazer, realização pessoal) e também objetivos (acesso a serviços públicos, seguridade social, proteção à vida privada e coletiva, liberdade de ser, ir e vir, capacidade de geração da subsistência e vida integrada aos sistemas oficiais... dentre outros), cujas referencias são a satisfação das necessidades básicas e das necessidades criadas pelo grau de desenvolvimento econômico e social de determinada sociedade. (Adaptado de PEREIRA et al, 2012, p.241).
} 
Nesse contexto, a Região Metropolitana do Rio de Janeiro (RMRJ) ${ }^{4}$, unidade territorial singular no contexto dos antecedentes históricos da organização territorial brasileira e da legislação sobre o tema no Brasil, vem sendo pensada e estruturada desde os anos de 1937 quando da Constituição brasileira, cunhada no Estado Novo, 'em seu artigo 29, inaugurou a previsão de agrupamento de Municípios da mesma região para a administração de serviços comuns, cabendo o Estado regular o meio de constituir-se o agrupamento e a sua administração' (SLAWINSKI, 2006, p. 214-215). No seu contexto evolutivo, tal concepção político-administrativa de região vem sofrendo inferências no mundo ocidental, notadamente em nível acadêmico e institucional no mundo europeu ibérico - e que afeta a produção acadêmica e institucional no Brasil, notadamente nos âmbitos da Ciência política, Direito constitucional, Geografia política, Gestão do território e as Política públicas - a partir das abordagens sobre a Responsabilidade Social do Território (RST) e o localismo ético, primorosamente trabalhados por Ferrão (2011), ao citar as abordagens de Del Baldo (2009) e Argiolas et al (2009) nessas direções também em suas recentes publicações.

Ainda segundo Ferrão (2011), o reforço das abordagens sobre parcerias público-privadas e as formas de governanças territoriais sobre as mudanças paradigmáticas da ação institucional dos Estados vêm substituindo, crescentemente, a concepção de 'governos' (um modelo moderno cunhado pelo estatal, burocrático, vertical...) por outra baseada em 'governanças', cujas coordenações entre atores e agentes são mais horizontais e verticais em projetos comuns). Nesse sentido, as discussões sobre possibilidades de gestão na imensa mancha urbana formada pela metrópole Rio de Janeiro ganham interesse pelos agentes institucionais. O escopo espacial e econômico dessas discussões vem sendo empenhado, competentemente, pela economista Sol Garson (2009) no Rio de Janeiro, que reforça a necessidade de ser reconhecido e encampado o debate ocidental sobre as potencialidades e gargalos das governanças locais e metropolitanas, discurso crescente na Europa e no Brasil, desde os anos de 1960. No caso europeu, esse interesse ocorreu como resultado da intensa urbanização e reconstrução das metrópoles

\footnotetext{
${ }^{4}$ A RMRJ é formada hoje pela conturbação de 21 municípios, com variações constantes, e agrega mais de 12 milhões de habitantes, a segunda mais populosa do país. Desse total, cerca de 6,5 milhões pessoas vivem no município-sede e capital da unidade federada Rio de Janeiro, formação territorial arquitetada em 1975, com a fusão político-administrativa da Guanabara com o Estado do Rio de Janeiro. Os municípios pertencentes à Região Metropolitana do Rio de Janeiro, desde 2014, são: Belford Roxo, Cachoeiras de Macacu, Duque de Caxias, Guapimirim, Itaboraí, Itaguaí, Japeri, Magé, Maricá, Mesquita, Nilópolis, Niterói, Nova Iguaçu, Paracambi, Queimados, Rio Bonito, Rio de Janeiro, São Gonçalo, São João de Meriti, Seropédica e Tanguá.
} 
europeias no pós-2 $2^{\text {a }}$ Guerra; no caso brasileiro, tal interesse foi enfraquecido frente às crises fiscal e política no país, nos anos de 1980. (GARSON, 2009)

Assim sendo e acompanhando as dinâmicas territoriais atuais, a pesquisa aqui apresentada buscará ampliar as discussões sobre a necessidade de serem observadas as metrópoles brasileiras (e o Rio de Janeiro, como reflexão empírica) como ambientes propícios para novas arquiteturas de gestão territorial, em que a cooperação e a coparticipação se tornem vieses atingíveis para a emergência de governanças sustentáveis para milhões de pessoas, diariamente. Tal situação será analisada sob duas perspectivas: 1) uma que vem sendo proposta pelo Plano Estratégico de Desenvolvimento Urbano Integrado da Região Metropolitana do Rio de Janeiro (PDUI/RMRJ) ${ }^{5}$, lançado pelo Governo do Estado do Rio de Janeiro, em 2015, com o sugestivo nome de 'Modelar a Metrópole', e que está sendo implementado pela Secretaria de Planejamento e Gestão do Estado do Rio de Janeiro (SEPLAG) no período atual (2017), quando o Estado do Rio de Janeiro vive a maior crise fiscal e financeira desde a fusão Guanabara-Rio de Janeiro, em 1975; e 2) o Projeto RIO METRÓPOLE ${ }^{6}$ - Progestão II, derivado do plano estratégico anteriormente exposto e que também financiado pelo Banco Mundial e do qual o GeTERJ é uma dos participantes na confecção de um sistema de informação integrado para a RM, como projeto político de governança cooperativa no Rio de Janeiro, a partir de 2018.

\footnotetext{
${ }^{5}$ No seu escopo, o 'Modelar a Metrópole' chama cariocas e fluminenses a pensarem juntos sobre estratégias de 'viver metropolitanamente', com a seguinte justificativa: o crescimento dos centros urbanos dos 21 municípios que compõem a Região Metropolitana do Rio de Janeiro torna urgente a busca por soluções conjuntas para os seus desafios sociais, econômicos e ambientais. (...), o Modelar a Metrópole está reunindo poderes públicos dos municípios, sociedade civil, instituições acadêmicas, empresariado e organizações de classe para elaborar um Plano Estratégico que oriente o desenvolvimento da Região Metropolitana do Rio de Janeiro rumo a um futuro com mais qualidade de vida, justiça social e igualdade. (Adaptado de http://www.modelarametropole.com.br/. Acesso em: 12 jul. 2017).

${ }^{6}$ Projeto vencido em licitação pública pelo pool NAT/PUC-Rio e uma empresa americana especializada em cartografia e Geoprocessamento, tem o objetivo de fortalecer a gestão pública e a assistência técnica ao desenvolvimento territorial integrado, com intuito de ampliar e avançar no processo de melhoria da gestão pública, objetivando atingir novos patamares de qualidade no gasto público, tendo como resultados melhor qualidade na prestação dos serviços públicos e no cotidiano da população fluminense. Tendo como premissa esses macro-objetivos, e considerando o relevante aporte de conhecimento e de experiências globais trazidas pelo Banco Mundial, a Secretaria de Estado de Planejamento e Gestão, coordenadora do Programa, em conjunto com o RioPrevidência, a Secretaria de Estado de Educação, a Secretaria de Estado de Saúde, o Instituto Estadual do Ambiente, a Secretaria de Estado de Defesa Civil e o Departamento de Recursos Minerais desenvolveram um plano de ação pautado nos desafios de gestão enfrentados pelas áreas centrais e finalísticas, através da especificação dos seguintes componentes técnicos: Componente 1: Sistemas Centrais de Governo e Ferramentas de Gestão para Melhor Desempenho e Eficiência; Componente 2: Fortalecimento da Capacidade de Gestão da Educação, Capacitação Docente Institucional e Incentivos para a Eficácia Escolar; Componente 3: Gestão de Saúde e Sistemas de Informação; componente 4: Desenvolvimento da capacidade institucional e tecnológica do mutuário para prevenção e atuação em eventos climáticos de alta intensidade; e Componente 5: Administração do Projeto. (Adaptado de http://www.progestao.rj.gov.br/. Acesso em: 12 jul 2017).
} 


\section{CONDICIONANTES PARA GOVERNANÇAS SUSTENTÁVEIS, COOPERATIVAS E COPARTICIPATIVAS NA REGIÃO METROPOLITANA DO RIO DE JANEIRO.}

Com base nas reflexões realizadas por Silva (2016) sobre as condicionantes metropolitanas de gestão cooperativa no Rio de Janeiro, a análise a seguir está situada nos pressupostos do Plano de Desenvolvimento Metropolitano, lançado em 2015 e em fase de conclusão (2017) pela Secretaria Estadual de Planejamento e Gestão (SEPLAG) do Estado do Rio de Janeiro. Também conhecido como o Plano 'Modelar a Metrópole', a proposta, subsidiada pelo Banco Mundial, reforça o planejamento metropolitano e sua gestão voltados para a construção de uma metrópole mais ordenada, justa, equânime, próspera e sustentável (SEPLAG, 2017), adjetivações importantes, porém sem impactos concretos se o processo de modelação proposto não for efetivamente conhecido e debatido.

A grande expansão urbana brasileira entre 1960 e 1980, notadamente nas capitais da macrorregião Sudeste do país, densificou as relações espaciais entre diversos núcleos integrados espacialmente, tornando a capacidade de gestão territorial fragmentada, devido às competências das escalas administrativas da legislação em vigor. Essa condição reflete-se na qualidade dos serviços prestados a milhões de pessoas, diariamente, por prefeitos isolados em seus territórios e desconectados das dinâmicas políticas dos Governos das Unidades federadas que, por sua vez, tentam se sustentar com os recursos públicos centralizados na União. A esquizofrenia territorial do modelo político brasileiro foi reforçada mais ainda pelas deliberações e costuras mal alinhavadas da Constituição municipalista de 1988, deixando passar, pelos gestores públicos e a própria população, a percepção espacial a qual Villela Souto (2005) se refere no seguinte trecho:

\footnotetext{
(...) é importante chamar a atenção para o detalhe que uma lei que institui região metropolitana pressupõe um fenômeno econômico, fático, social e urbanístico, que é a conurbação. Portanto, quando existe uma conurbação, os interesses são interpenetrados, não se percebe mais onde termina um município e começa outro, e ai não se pode falar mais em interesse predominantemente local; o interesse passa a ser regional, sendo isso que viabiliza escala entre todos. (p.156) (grifo nosso).
}

No caso da Região metropolitana do Rio de Janeiro, a concentração de $72 \%$ da população da unidade federada em somente $23 \%$ dos seus municípios faz com que a observação do jurista destacada acima seja ainda mais expressiva, considerando-se a importância demográfica dessa macrorregião. No 
cartograma a seguir, é fácil localizar os 21 municípios metropolitanos, apenas observando-se o percentual de áreas urbanas no território da unidade federada.

Tal perfil urbano da unidade tem a sua história na constituição do Município Neutro do Império brasileiro, em 1834, que, em 1891 foi transformado em Distrito federal permanecendo assim até 1960 quando foi incorporado ao antigo Estado do Rio de Janeiro, em 1975. A histórica separação territorial do município do Rio de Janeiro da antiga Província fluminense deixou marcas profundas, sejam elas sociológicas, antropológicas ou geográficas nos seus habitantes e territórios. Enquanto o perfil cosmopolita da cidade do Rio de Janeiro consolidou-se na população carioca como uma marca da urbanidade e capitalidade na prestação de serviços diversos na escala nacional, associados à modernidade da gestão central do país advinda do seu território (situação mantida mesmo após a cidade ter perdido a sua condição de capital do Brasil, em 1960), o antigo estado do Rio de Janeiro manteve o seu tradicional perfil rural associado às atividades primárias do período colonial e agrárioexportador, situação pouco modificada até a chegada, via Planos Nacionais de Desenvolvimento (PND I e II), dos projetos de modernização logística e energética dos Governos militares para o estado, notadamente a partir da fusão político-administrativa e territorial das duas unidades federadas, Guanabara e Rio de Janeiro, em 1975.

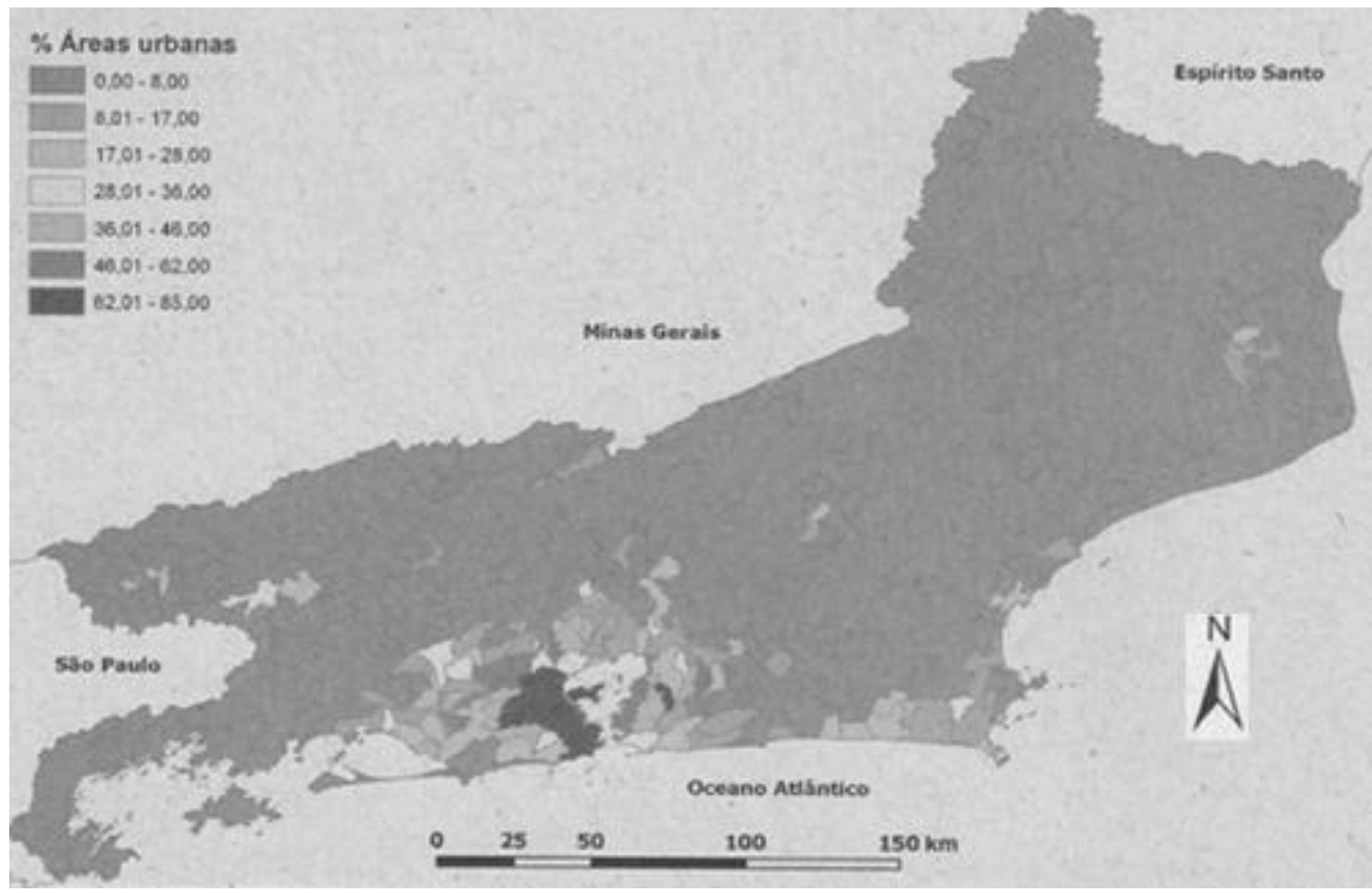


Mapa 2. Manchas de expansão urbana no território do Estado do Rio de Janeiro. FONTE: Adaptado de INEA (2010).

Todavia, deve-se considerar que, desde meados do século XIX, e, com maior intensidade, ao longo do século XX, a periferia imediata do Município Neutro (mais tarde, o Distrito Federal) foi gradualmente desestruturada do seu perfil rural para outro mais urbano, o que possibilitou a ampliação dos seus núcleos habitacionais, mantidos tímidos até o início do século XX. Como reflexo desse processo urbanizador, a região (que, mais tarde, passaria a ser nomeada de Baixada fluminense e conhecida, nacional e internacionalmente, pelos seus índices de pobreza crônica e violência explícita) teve a sua população exponencialmente ampliada em um período de menos de um século, recebendo muitos habitantes em seus municípios vindos do território carioca (pobres que se retiravam da cidade do Rio de Janeiro pelo alto valor do solo urbano, dos impostos e taxas gerados pelas diversas reformas urbanas, ao mesmo tempo em que eram atraídos para a Baixada fluminense por políticas públicas específicas de urbanização da área com o desmonte, pelo poder central, das atividades primárias dos municípios limítrofes à capital federal) quanto migrantes vindos, notadamente, dos municípios do interior do estado do Rio de Janeiro e de Minas Gerais, além dos da macrorregião Nordeste do país, populações que eram afetadas por diversos níveis de escassez. Com a ampliação numérica, simultaneamente, da população carioca e dos municípios limítrofes na faixa imediata da fronteira do Distrito Federal, outrora o 'cinturão verde da capital do país', a conurbação foi sendo concretizada ao longo do século XX, ao mesmo tempo em que o antigo estado do Rio de Janeiro perdia quantidades absolutas de população, esvaziando-se os municípios, situação que perduraria até os anos de 1990 (SILVA, 2005, 2015).

Nesse contexto de possibilidades e urgências trazidas pela crise fiscal e política atual do país, (e, especificamente, a da unidade federada Rio de Janeiro, depois de quase uma década - de 2006 a 2014 - de uma falsa sensação de crescimento e consolidação de investimentos no território fluminense - a partir da estreita articulação política entre os Governos da União e da Unidade federada, resultando em uma marginalização do papel dos municípios nos processos de desenvolvimento local / regional, entre 2002 e 2015) é que novas formas de gestão dos territórios voltaram 'à crista da onda', para que 
sejam tentadas mudanças sustentáveis nas formas sobre as quais as políticas públicas devem ser pensadas e aplicadas em espaços conurbados e regionais.

Como resultante das políticas públicas dos Governos centrais brasileiros para a modernização do novo Estado do Rio de Janeiro com a fusão de 1975, algumas importantes redes infraestruturais (como as de gás e óleo), rodovias e outros aspectos associados à natureza (projetos de proteção à Mata Atlântica) podem ser observados no espaço fluminense; todavia, as maiores transformações foram realizadas no território carioca, desde então, tanto por Governos municipais quanto estaduais. A seguir, um cartograma dessas marcas espaciais que precisam de uma intersecção para um projeto integrado de desenvolvimento que considere a complexidade de um território pensado geopoliticamente.

Assim sendo, ao retornarmos ao objetivo da discussão federalista no Brasil, anteriormente comentada, o escopo geral do Plano 'Mudar a Metrópole' resgata o principal tema das discussões sobre as competências dos três níveis (União, Unidades Federadas e Municípios) de gestão territorial no Brasil do período republicano: a desconcentração dos investimentos da core area metropolitana, ou seja, do município do Rio de Janeiro. Com base na legislação sobre o tema e as reflexões mais do que pertinentes de Grau (1974) sobre o conceito de 'função metropolitana', o jurista afirmava, no Plano Metropolitano de Desenvolvimento Integrado da Grande São Paulo, em 1971, que as tais das funções metropolitanas são:

... atividades e serviços urbanos, ou parte destes, que, pela natureza de sua disciplina, implantação ou operação, resultem em conexões e interferências recíprocas entre diferentes municípios, exigindo ação unificada e planejada que ultrapasse seus limites institucionais. Para que o conceito possa ser aplicado, indistintamente, a qualquer realidade metropolitana, basta que se substitua a expressão 'diferentes municípios' por 'diferentes unidades administrativas com atuação na área'. (...) (PLANO METROPOLITANO DE DESENVOLVIMENTO INTEGRADO DA GRANDE SÃO PAULO, 1971, p.189). 


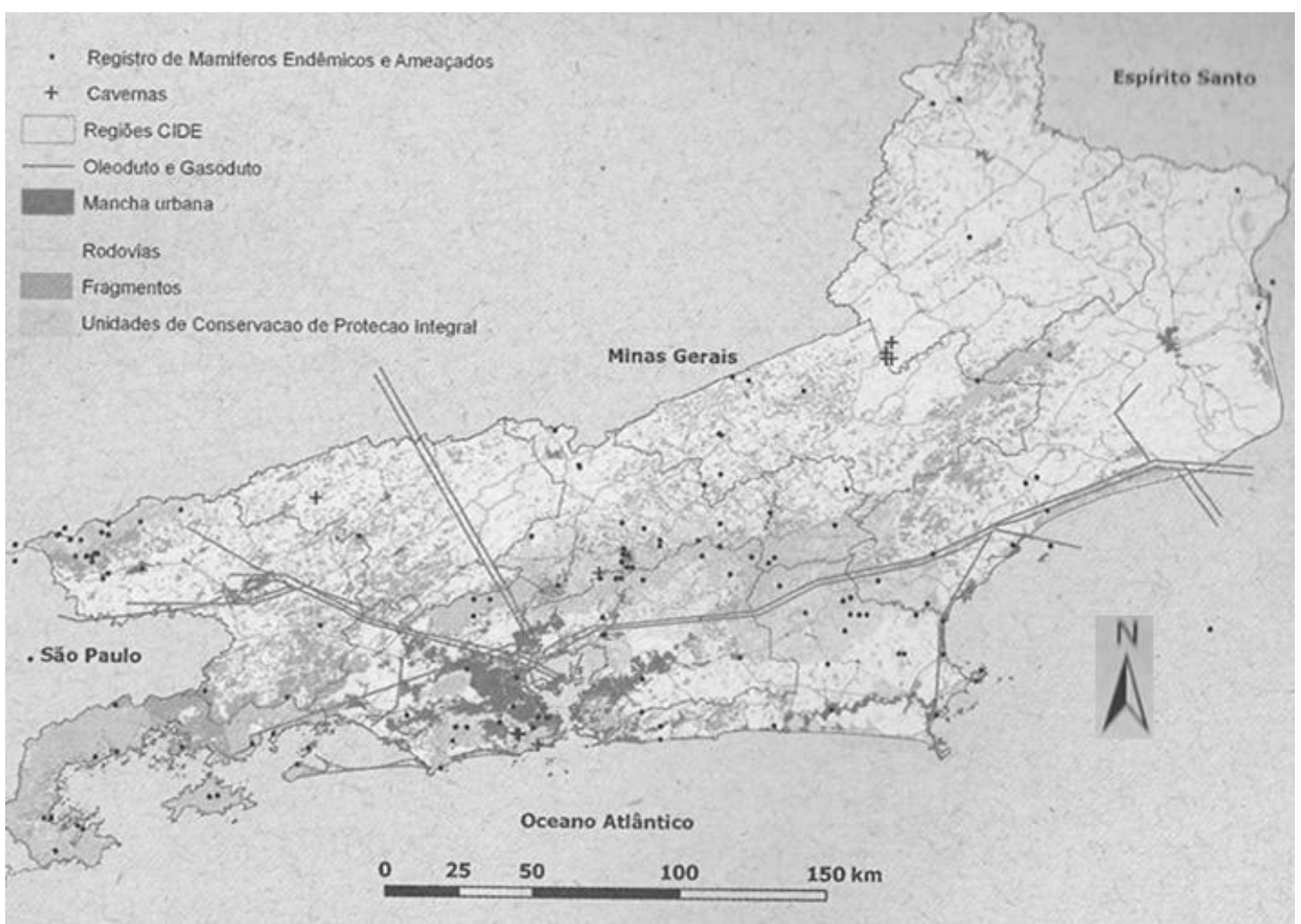

Mapa 3. Aspectos urbanos, logísticos e ambientais no território fluminense. FONTE: Adaptado de INEA (2010).

Levando-se em conta essa importante referência político-administrativa (gestada nos Atos Institucionais de 1967, durante o período de exceção do Estado brasileiro), a ideia foi sendo adensada pelos juristas envolvidos na legislação metropolitana daquela época e que ampliaram as reflexões sobre os temas metropolitanos em tempos mais recentes. Dentre elas, ressaltam-se nesse artigo as visões de Alves (1998) e Grau (2000) sobre como as funções metropolitanas devem se tornar públicas. Para esses juristas, as regiões serão consideradas, de fato, metropolitanas quando certos serviços nelas presentes e oferecidos tenham um tratamento comum e integrado, dando forma pública às funções existentes, ou seja, integrando-se vários municípios a partir da oferta comum e horizontal deles, entendendo-se tal dinâmica como de 'interesse comum entre o poder municipal e a União, o que deveria promover uma 'gestão unificada" (SLAWINSKY, 2006, p. 216), ou seja, "uma gestão conjugada de todas as entidades autônomas que existem no limite de uma região metropolitana' (Idem, p. 217).

Tal abordagem se justifica pela necessária confiança político-institucional instituinte a ser criada a partir de uma sociedade supraterritorializada - entendendo-se tal concepção como a correlação de 
ações conjuntas envolvendo atores sociais e agentes da política territorial interessados em tornar públicas as funções existentes e que devem ser de usufruto coletivo na região. Esse modelo de governança cooperativa, mais do que resultante de ações de Governos, deve se comportar como um sistema de vasos comunicantes ${ }^{7}$, como as leis da Física mostram através do sistema hidrostático apresentado a seguir.

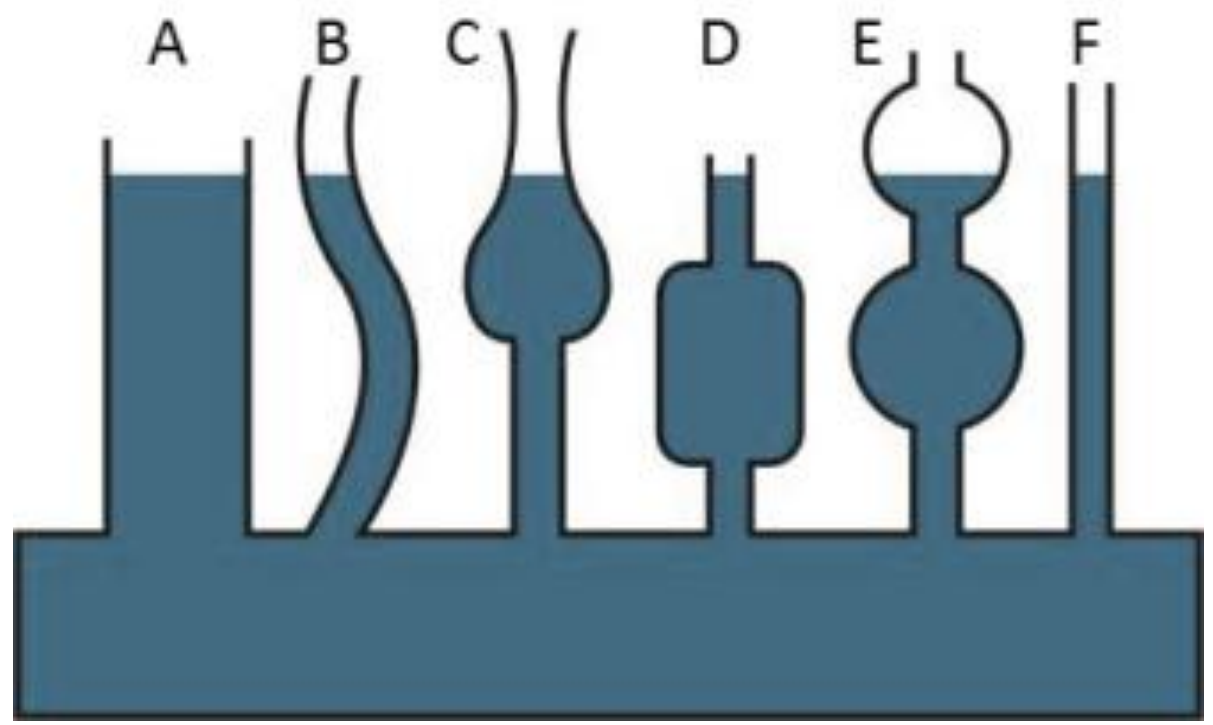

Esquema. Sistema de vasos comunicantes. FONTE: Adaptado de http://www.ebah.com.br/. Acesso em: 12 ago. 2017.

Levando-se em conta essa importante referência político-administrativa (gestada nos Atos Institucionais de 1967, durante o período de exceção do Estado brasileiro), a ideia foi sendo adensada

\begin{abstract}
Esse sistema apresentado, na explicação das leis da hidrodinâmica, é
(...) um conjunto de vasos, dois ou mais, que são postos em comunicação entre si de tal modo que um líquido que se deite num deles se distribui por todos os outros. Nessas circunstâncias, qualquer que seja a capacidade particular de cada um dos vasos ou a sua posição relativa no conjunto deles - supondo-os abertos, as superfícies livres do líquido, nos vasos comunicantes, ficam situadas, em todos eles, ao mesmo nível. Poder-se-ia pensar que o líquido contido em A, por exemplo, pelo fato deste possuir maior diâmetro do que B e, portanto, conter uma porção de
\end{abstract}

\footnotetext{
${ }^{7}$ Apesar de a ideia de que 'o mundo não é um sistema de vasos comunicantes', como afirma o Prof. Walter Belik, da Unicamp e formado pela EAESP-FGV/SP, que vem de uma trajetória de pesquisas relacionadas à avaliação de políticas agrícolas e agroindustriais na escala mundial, concentrando as suas atenções nos aspectos do processamento, logística e distribuição de alimentos como fatores determinantes para o sucesso de políticas alternativas de segurança alimentar, acreditamos que, sem política séria e geograficamente sustentável, não se criam pontes nem se derrubam muros para a ação e o reconhecimento das responsabilidades social na escala da gestão. O nosso contraponto com a visão do renomado pesquisador é em relação à ideia de que a desconcentração e redistribuição precisam ser pensadas politicamente em múltiplas escalas, para que as desigualdades socioespaciais não criem mais esgarçamentos e tensões, notadamente em ambientes demograficamente milionários.
} 
líquido de maior peso, obrigasse esse mesmo líquido a ascender mais em A. Tal situação não se sucede. O que ocorre é o equilíbrio do líquido e esse equilíbrio exige, segundo a lei fundamental da Hidrostática, que a pressão tenha igual valor em todos os pontos situados a um mesmo nível, o que só se verifica quando as superfícies livres do líquido nos diferentes vasos estiverem todas no mesmo plano horizontal. (Adaptado e traduzido de DELGADO et al, 2004, p.369).

Em analogia com a lei da Física apresentada, o tema central deste trabalho - a Geografia política torna-se factível e desejável. Adaptando-se a tradução da obra espanhola acima sobre os vasos comunicantes à dinâmica de gestão metropolitana cooperativa desejada, tem-se a seguinte adaptação: uma região integrada por municípios coligados em uma governança cooperativa é formada por unidades políticas que recebem de fontes diversas (e de agentes e atores locais, inclusive), a mesma política pública. Apesar das características particulares e singulares de cada município da região e a sua posição locacional no sistema regional, cada um deles (os municípios) terá o mesmo nível de impacto da medida unificada, mesmo sendo desiguais, já que o sistema é livre de imposições externas e aberto ao equilíbrio endógeno que objetiva tornar públicas e equânimes as funções existentes naquele espaço. Como o objetivo é o equilíbrio espacial das funções públicas (para haver sustentabilidade das ações políticas), os municípios mais ricos (ou com menor demanda em relação à função existente que está em foco) participarão mais do processo distributivo usando suas forças de pressão e atuando com a mesma intensidade política que os municípios mais carentes dessas funções deverão usar. Assim sendo, a política pública por todo território regional fará com que a função pública seja mais saudável, ampla e plural, pois que ela foi redinamizada por políticas públicas específicas que as reforçou com o seu direcionamento mais intenso para onde há maior escassez da função. Equilibrando-se esta por toda malha regional, a concepção de função pública é atingida para o setor e novas ações terão a mesma lógica, porque cada unidade municipal terá potencialidades capazes de suprir faltas e carências em outro ponto do sistema regional de funções públicas.

A partir da analogia apresentada, observa-se como o objetivo do Projeto 'Modelar a Metrópole' na Região Metropolitana do Rio de Janeiro propõe o compartilhamento de serviços comuns entre os territórios municipais mais carentes de uma ação mais efetiva dos municípios mais fortes regionalmente. Um primeiro caminho é resgatar o ambiente de credibilidade institucional para que sejam eliminadas as crônicas crises de governabilidade entre as escalas município-município e 
município-unidade federada. Assim sendo, a flexibilização de orçamentos municipais para a definição de projetos associados às demandas regionais nesse jogo de comunicação 'comunicante' intermunicipal, adequará os recursos dos orçamentos locais entre os vários municípios regionalizados, descentralizando os recursos estaduais pelo jogo da pressão política suprapartidária, por exemplo, no campo da luta social local.

Releva-se, também, o fato de os juristas aqui citados terem uma dimensão não geográfica das funções metropolitanas, ao considerarem, assim como Grau (1974) que:

(...) nas regiões metropolitanas (as atividades e serviços urbanos), uma parte delas pode consubstanciar função metropolitana e outra não. É o caso, por exemplo, da função 'abastecimento de água', onde a captação, adução e tratamento não prescindem de uma administração unificada (município-unidade federada-união, por exemplo), sendo de interesse estritamente local, (...) (p.36) (grifo nosso)

A afirmação acima desqualifica as discussões sobre as gestões integradas por bacias hidrográficas, por exemplo, restringindo as unidades de gestão territorial aos pressupostos legais das competências dos três níveis do federalismo brasileiro. Atualmente, todavia, tal concepção vem sendo reconsiderada pelas dinâmicas políticas desenvolvidas por diversos comitês de bacias hidrográficas pelo Brasil que, além de considerarem os limites da gestão territorial de águas (na verdade é uma confluência de decisões de níveis de poder com competências e escalas variadas - governos municipais locais, governos estaduais, União, movimentos sociais, representações de classe e de bairros...), reforçam tais políticas setoriais, com múltiplas competências, em torno do abastecimento de água em projetos de ocupação e uso das bacias sobre as quais os municípios estão assentados.

Nesse sentido e levando-se em conta os aparatos espaciais sobre os quais os serviços essenciais devem ser oferecidos como funções metropolitanas na RMRJ, algumas tópicos mais específicos aqui se fazem necessários no momento da pesquisa em curso. A unidade territorial em referência não pode conceber uma gestão ambiental integrada em águas salgadas isolada nas competências municipais. Tal gestão deve envolver o equilíbrio do ecossistema marítimo, o controle das atividades industriais e de circulação, a observação diligente sobre as atividades recreativas, pesqueiras e turísticas em um litoral tropical repleto de especificidades, a renovação de um processo de urbanização litorâneo descontrolado 
e especulativo, a reestruturação da complexa rede logística de abastecimento de gás e óleo para a metrópole e outras regiões do território brasileiro dentre outros importantes fatores - sem que se considere, essencialmente, a presença de duas baias circundantes à cidade. O surgimento e a consolidação da cidade do Rio de Janeiro deu-se no litoral de uma das mais famosas baias do mundo, a de Guanabara, e o seu processo de ocupação e uso foi e é largamente estudado por geógrafos (com destaque para o professor Elmo da Silva Amador ${ }^{8}$ ), biólogos, ecólogos, oceanógrafos, cientistas ambientais e pesquisadores de outras áreas do conhecimento. Desde os anos de 1960, a metrópole cresce, demográfica e economicamente, na direção Oeste e se encontra com a Baia de Sepetiba no seu limite continental sul. Desde então, as pesquisas sobre essa baia ganham novas intensidades ${ }^{9}$, mas são ainda muito mais tímidas, comparativamente, às realizadas sobre a Guanabara. Todavia já se comprova com os dados socioambientais levantados nessas pesquisas (muitas delas ligadas aos capitais corporativos dos grandes investimentos para a implementação de complexos industriais e portuários lá alocados, notadamente pós-1970) que as mesmas dinâmicas urbanas, logísticas e infraestruturais que arrasaram socioambientalmente as margens da Baia de Guanabara, ao longo dos quase 500 anos de presença do homem ocidental no seu litoral, se repetem na Baia de Sepetiba, em um ritmo avassalador, pois as externalidades negativas cresceram em um ritmo exponencialmente preocupante em apenas em algumas décadas. Reforça-se a ideia de que os serviços prestados em águas marítimas nas duas baias deva ter uma função metropolitana central, já que dos seus 21 municípios, 08 são banhados pelas duas baias, e dentre esses 08 municípios, 05 são os mais povoados do estado (Rio de Janeiro, São Gonçalo, Niterói, Duque de Caxias e Nova Iguaçu) e centralizam os investimentos econômicos e logísticos do território estadual.

\footnotetext{
${ }^{8}$ A obra síntese da trajetória do professor do Departamento de Geografia da UFRJ foi escrita a partir da atualização da sua pesquisa sobre a avaliação ambiental da Baia de Guanabara, em 1997. Em 2007, três anos e falecer, ele entregou à editoração da obra citada neste trabalho, que é um compêndio absolutamente necessário para os pesquisadores do e sobre o Rio de Janeiro. Nessa publicação, Amador (2013) traz informações, observações e reflexões preciosas para o nosso tempo sobre esse grande espelho d'água, cantado em verso, prosa e imagem por todo o mundo, remontando a história geológica, biológica e antropológica em torno deste símbolo brasileiro que é a Baía de Guanabara.

${ }^{9}$ Recomenda-se, como base de boas referências sobre artigos e bibliografias de pesquisas diversas sobre a Baia de Sepetiba, o documento diagnóstico gerado pelo Instituto Políticas Alternativas para o Cone Sul (PACS), fonte para importantes pesquisas socioespaciais futuras sobre esse imenso espelho d'água que envolve tantas questões essenciais para a qualidade de vida metropolitana, no Rio de Janeiro, no futuro. O endereço eletrônico desse importante relatório diagnose chamado de 'Baía de Sepetiba: fronteira do desenvolvimentismo e os limites para a construção de alternativas' é: http://www.pacs.org.br/files/2012/12/Ba\%C3\%ADa-de-Sepetiba-fronteira-do-desenvolvimentismo.pdf. Acesso em: 12 jul. 2017.
} 
Outra especificidade sob a lógica de construção de funções metropolitanas para os serviços essenciais a serem prestados pela rede de governança na RMRJ deve ser voltada para os sistemas de captação de água potável e sua distribuição espacial assim como os de saneamento básico e logístico para a coleta e tratamento de esgoto doméstico e industrial, temas intensamente discutidos nos estudos institucionais aqui citados (as concepções de funções municipais X funções metropolitanas de GRAU, 1974; FERRAZ, 1976; TÁCITO, 2002; VILLELA SOUTO, 2005, GARSON, 2005, dentre outros). Compreendida entre duas grandes 'regiões hidrográficas' (Região hidrográfica Baia de Guanabara RH V - e Região hidrográfica Guandu - RH II), a RMRJ deve, nestes temas, ser coordenada pelos comitês de bacias hidrográficas responsáveis pelas articulações político-institucionais das regiões II e V supracitadas, que se tornam espaços políticos (CASTRO et al, 2013) para as discussões e deliberações sobre os serviços essenciais elencados anteriormente. Assim sendo, a população metropolitana como um todo ganhará (e não apenas parte dela) nos fóruns municipais, o que pode reduzir um problema até agora insolúvel: a redefinição das competências, suas escalas e territórios de gestão para questões de abrangência espacial bem mais ampla ${ }^{10}$.

Um terceiro ponto específico relacionado à escala metropolitana do Rio de Janeiro (mas que é indubitavelmente um dos nós górdios hoje para a gestão de áreas metropolitanas em diversos países periféricos e semiperiféricos da atualidade) refere-se à mobilidade urbana. A falta de um sistema intermodal que integre tanto o espaço interregional metropolitano quanto a RMRJ às demais regiões

\footnotetext{
${ }^{10}$ Sobre este tema é fundamental a compreensão de um dos maiores fracassos de gestão pública no estado do Rio de Janeiro até hoje: o Programa de Despoluição da Baia de Guanabara (PDBG), iniciado em 1995. Ao ser desconsiderada a escala dos eventos geográficos que provocam a poluição nessa baia, o PDBG, que foi setorizado, acabou não atendendo ao planejado pelo Governo do Estado do Rio de Janeiro, gerando o desperdício de gigantescos investimentos internacionais, notadamente os advindos dos bancos japoneses. A incapacidade de gestão sobre o processo de redução de lançamento de dejetos no espelho d'água dessa baia está, em parte, associado à falta da dimensão do fator geográfico 'bacia hidrográfica' como unidade de gestão. Nesta dimensão deve ser observada a capacidade de captação de todo sistema de esgotamento sanitário existente e, através de ações conjugadas, deve-se aperfeiçoar tal sistema e estendê-lo para onde ele não existe, conectando-se todo o sistema de captação para tornar eficiente todo o processo de coleta e transporte de esgotamento sanitário doméstico e industrial. Todavia, o sistema foi fragmentado por ações isoladas e de maneira a beneficiar 'os interesses específicos de alguns municípios'. Sem integração horizontal de tal dinâmica que deve ser referendada por comitês de bacias hidrográficas os resultados negativos não tardam a aparecer. Além desse importante fator, as dinâmicas de crescimento urbano precisavam ser monitoradas através de um sistema metropolitano que respeitasse as margens dos rios que desaguam na baia, assim como as áreas ribeirinhas e de manguezal do litoral desse espelho d'água. Para uma melhor compressão do tema e dos desmandos de tal megaprojeto, recomenda-se a leitura da dissertação de mestrado de Vieira (2009), 'O Programa de Despoluição da Baía de Guanabara. Entraves institucionais e impactos territoriais na Região Metropolitana do Rio de Janeiro', defendida no PPGG do Departamento de Geografia da UFRJ.
} 
do estado fluminense reduz a eficiência de atrair investimentos diversos, que são, em linhas gerais, promotores de emprego e renda. O recém-construído Arco Rodoviário Metropolitano, interligando os municípios de Itaboraí ao de Itaguaí (e passando por mais outros seis municípios metropolitanos) criou importantes conexões intermunicipais na megarregião MRJ, notadamente em municípios chave na Baixada fluminense, sub-região metropolitana com graves e históricos problemas de violência implícita e explícita. Todavia, a falta de um sistema intermodal diverso (sistemas ferroviário, operado pela Supervia, somente para passageiros, e hidroviário, operado pela CCR Barcas tanto na Baia de Guanabara como na de Sepetiba, somente para passageiros também) sobrevaloriza o modal rodoviário tanto intramunicipal (como é o caso dos BRTs, na cidade do Rio de Janeiro) quanto intermunicipal (o domínio da empresa 1001 no território fluminense é quase absoluta) tanto para o transporte de carga quanto para o de passageiros. A carência de opções de modais, notadamente os não rodoviários, na escala intermunicipal gera um dos maiores problemas de serviços públicos essenciais oferecidos aos cariocas e fluminenses: a ineficiência da mobilidade metropolitana. Milhões de pessoas sofrem diariamente com a falta de opções para circular na mancha metropolitana do Rio de Janeiro devido também à cartelização, por empresas privadas, dos sistemas de transporte. Tais empresas, por sua vez, têm o controle político das agências reguladoras, que agem como máquinas políticas de apoio ao sistema ineficiente, gerando um ciclo de insatisfação generalizada para os milhões de circulantes diários da metrópole Rio de Janeiro ${ }^{11}$.

Um dos tópicos específicos mais importantes que necessita do resgate da função metropolitana nos dias atuais, sob a base regional, e, portanto, a discussão sobre um modelo de gestão que ressignifique os entes federativos 'não como mais um governo, mas sim como mais e melhores governanças' se refere ao sistema metropolitano de recolhimento e deposição de resíduos sólidos. Baseada ainda em sistemas municipais cuja responsabilidade recai sobre as Prefeituras, cremos ser de interesse coletivo na escala regional que a função social das atividades relacionadas ao recolhimento, transbordo e deposição de

\footnotetext{
${ }^{11}$ Para o aprofundamento no tema, recomenda-se a leitura apurada da excelente dissertação de mestrado de Pacífico (2013) intitulada 'Transporte Aquaviário de Passageiros na Baía de Guanabara (RJ): monopólio e gestão das acessibilidades em uma perspectiva geográfica', defendida no Programa de Pós-Graduação em Geografia (PGE), da PUC-Rio. Em abril de 2018 será defendida mais uma dissertação de metrado sobre o tema 'Mobilidade no Rio de Janeiro' no mesmo PGE, com o tema de resgate do modal ferroviário de passageiros entre os municípios fluminenses e intermetrópoles do Sudeste. 0 autor da pesquisa é o mestrando Pável Grass.
} 
resíduos ganhe relevância e efetividade no âmbito metropolitano por serem os resíduos e o seu mal manuseio público um dos temas que mais causam efeitos devastadores na qualidade de vida de milhões de pessoas. Referendar a discussão regional sobre o tema leva para a escala da gestão compartilhada as decisões sobre os espaços a serem 'sacrificados' para a boa coordenação regional sobre o tema. Os debates sobre os temas: aterros sanitários, usinas de tratamento de resíduos, usinas de compostagem, centros de transbordo e seleção de resíduos...são sempre traumáticos em termos territoriais devido ao sacrifício imposto a determinados espaços que terão os seus valores simbólicos e concretos desabarem sob diversas perspectivas. Do valor do preço da terra às doenças endêmicas associadas a vetores diversos, passando pela poluição do ar e sonora imposta pelo tráfego constante de caminhões transportadores mal cheirosos e barulhentos, os espaços metropolitanos definidos para essas funções precisam ser mediados por fortes contrapartidas acordadas sob termos efetivamente justos para milhões de pessoas. Assim como os royalties são recursos advindos como contrapartidas aos graves problemas socioambientais locais gerados por externalidades nocivas na exploração de recursos diversos, por exemplo, os serviços essenciais associados aos resíduos devem beneficiar os territórios escolhidos através de uma rede de ação política e social em prol de um bem comum. Maiores investimentos podem ser direcionados para as mesmas áreas para a geração de emprego e renda, como também em temas relacionados ao reflorestamento, cuidado com as águas públicas e mais atendimento médico-hospitalar. Tais contrapartidas devem compensar o ônus do recebimento dessa carga sistêmica no setor como forma de conter, pelo menos em parte, os corpos doentes ${ }^{12}$ que surgirão nas zonas de sacrifício.

Finalmente, como último ponto das especificidades aqui destacadas ${ }^{13}$ envolvendo o Rio de Janeiro tema que não é singular a essa metrópole, mas que emerge como um dos mais graves problemas de

\footnotetext{
${ }^{12} \mathrm{O}$ tema merece atenção redobrada de pesquisadores e gestores. Para uma melhor compreensão sobre o tema no município do Rio de Janeiro, recomenda-se a leitura da dissertação de mestrado de Paulo (2015). Intitulada de 'Sobre resistência e resignação: o exercício do poder político no combate à produção de corpos doentes', a geógrafa faz uma excelente narrativa sobre como os poderes instituídos definem as zonas de sacrifício em cidades metropolitanas como a do Rio de Janeiro e assim aprisionam corpos que adoecem em territórios afetados por políticas públicas injustas para com aqueles que têm menos inserção política e força de pressão. Fazendo analogia com a ideia de prisão e cárcere em Foucault, ela eleva a prisão ao espaço e dele vindo a produção de corpos doentes.

${ }^{13}$ Educação e Saúde públicas são temas recorrentes nas discussões sobre os serviços coletivos que precisam ser melhorados urgentemente. Como são temas absolutamente básicos para todos os lugares, a pesquisa em curso deixou tal reflexão para
} 
ordem coletiva a ser enfrentado sob a égide das funções metropolitanas (e das responsabilidades sociais dos territórios através das novas governanças) - destaca-se o sistema de segurança pública. Um dos mais expressivos e impactantes problemas da atualidade cotidiana das metrópoles brasileiras, a violência explícita possui raízes históricas singulares na estruturação regional do Rio de Janeiro. Dentre os mais variados processos geradores da violência cotidiana nas cidades latino-americanas e, com destaque nas cidades brasileiras (desde o processo colonial, o massacre dos povos locais, as desiguais divisões territoriais reforçadas pela manutenção dos privilégios de grupos políticos nas esferas de decisão dos diversos níveis do poder público... até a manutenção dos esgarçamentos dos tecidos socioespaciais no ambiente metropolitano atual), as discussões sobre os níveis de violência estrutural na cidade do Rio de Janeiro e suas periferias ganhou destaque na pesquisa acadêmica e no próprio desenvolvimento da identidade carioca/fluminense que, institucionalmente, afetam as análises sociológicas, historiográficas e geográficas de um tema constante para a decisão sobres políticas públicas a serem implementadas nesse eixo metropolitano. O reconhecimento institucional de que a violência é um aspecto presente no ethos dos cariocas e fluminenses metropolitanos ${ }^{14}$ destaca o tema nas decisões de alocação de investimentos públicos e privados nos territórios que compõem a mancha metropolitana da região e definem um padrão de 'qualidade de vida metropolitana' cujo tema

artigo a ser produzido proximamente frente à importância de se verificar tal debate na escala federativa e para além das regiões metropolitanas e RIDES do país.

${ }^{14}$ As abordagens sobre a violência no Rio de Janeiro são amplamente pesquisadas e discutidas. Seus temas que passam por: a condição de cidade balneária e periférica no ambiente colonial português na América do Sul entre os séculos XVI e XVIII e a violência institucional das corruptas burocracias portuguesas, as tensões, cooptações e devastações culturais geradas pelos conflitos dos Estados europeus com os ameríndios (e o seu extermínio) por todo o recôncavo da Guanabara, a destruição ambiental da mesma baia, com destaque para a sua vida marinha, a inviabilização de navegabilidade dos rios da bacia da Baia de Guanabara e a pobreza estrutural gerada pelas doenças endêmicas e epidêmicas que assolaram todo o fundo da baia e os leitos dos seus rios contribuintes, ao longo de 400 anos (e que retornaram, exponencialmente, nas últimas décadas do século XX), a divisão territorial separando-se o Município Neutro do Rio de Janeiro (ou Município Real) e a Província fluminense, em 1834, criando-se vários problemas de ordem econômica, sociológica e antropológica no contexto do Rio de Janeiro, as constantes mudanças dos estatutos político-jurídicos da cidade do Rio de Janeiro e as violentas intervenções urbanas da 'era da modernidade', o que gerou a derrubada de morros, dessecamento de várzeas, rios, lagunas, o desaparecimento de restingas, mangues, alagados importantes para o ecossistema tropical ao ser expandido o espaço de ocupação urbana, industrial e de circulação nos litorais oceânico e interior (da Baia de Guanabara), a ineficiência das políticas habitacionais na metrópole e a banalização do tema 'favelização da cidade' há mais de um século, a ação do poder público da União (e a ineficácia do 'poder local' quando a cidade do Rio de Janeiro ocupou o papel de Distrito Federal - 1891-1960) de eliminação das atividades agrícolas e áreas verdes na região hoje conhecida como Baixada Fluminense em prol de um projeto industrialista e devastador das condições socioambientais nas periferias intermetropolitanas, a presença de uma polícia militar repressora e corrupta, com funções herdadas do período regencial no século XIX, e que não representa os anseios das populações locais por bem estar e proteção (pois imiscuiu-se de relações incestuosas com o crime organizado), dentre outras situações históricas, sociológicas, espaciais, ambientais, que são amplamente pesquisadas e divulgadas por investigadores diversos e em tempos múltiplos. 
'violência' precisa ser contextualizado, mensurado e analisado. Atualmente, o tema 'Unidades de Polícia Pacificadora' $(\mathrm{UPP})^{15}$ referenda-se como a última grande política pública pensada para a cidade carioca e ampliada para a sua RM, com o objetivo de erradicação das causas da violência estrutural no Rio de Janeiro e que hoje se concentram no controle, pelo narcotráfico subdividido em facções diversas e articulado com os poderes oficiais, nos grandes complexos de favelas e bairros periféricos da cidade e sua RM.

No Projeto 'Modelar a Metrópole', as articulações em curso não dão prioridade ao combate da violência, em diversos níveis, de forma direta e proativa. 0 combate das formas concretas de violência, que afastam investimentos diversos e promovem o crescimento econômico deveria ser focado em um política de segurança metropolitana que articula-se: a) a fusão das polícias militar e civil em uma única corporação desmilitarizada capaz de combater, com inteligência, setores da economia ilegal que dominam parte do poder instituído na metrópole; b) um sistema de combate à entrada de armas no estado do Rio de Janeiro através de uma articulação entre a polícia reformada, a Polícia federal e o Exército, em um processo de articulação regional que envolvesse, no policiamento ostensivo, as guardas municipais que atenderiam demandas locais mais específicas do cotidiano da mancha metropolitana (vigilância de bairros, policiamento ostensivo de estradas, controle sobre a circulação de cargas em áreas onde os roubos são frequentes... Ou seja: além dos focos na reestruturação econômica, no modelo de mobilidade e difusão de infraestruturas e no resgate dos patrimônios ambiental e cultural, uma cultura de proteção, incorporação e ação de investigação e buscas inteligentes, com um bom sistema de vasos comunicantes entre os municípios, deveriam ser prioritárias para estruturação de uma governança cooperativa e sustentável na Região Metropolitana do Rio de Janeiro.

\section{ALGUMAS REFLEXÕES PARCIAIS}

\footnotetext{
${ }^{15}$ Para melhor conhecer tal dinâmica de política pública, recomenda-se a leitura atenta da ótima dissertação de mestrado defendida por Valle (2016), no Programa de Pós-graduação em Geografia da Faculdade de Formação de Professores da UERJ (FFP-UERJ). Intitulada de 'As implicações territoriais da pacificação de favelas: um estudo sobre a Unidade de Polícia Pacificadora na Mangueira', a dissertação de mestrado do atual doutorando reflete sobre as especificidades da UPP da Mangueira sem perder o foco explicativo sobre essa importante política pública que teve efeitos diversos, temporal e espacialmente, desde o seu início em 2008. Atualmente as UPPs, frente à crise orçamentaria vivenciada pelo Governo do Estado do Rio de Janeiro está praticamente desativada e a violência implícita volta a aumentar.
} 
O projeto Modelar a Metrópole, iniciado em 2015, tem produzido um farto material institucional a partir das parcerias dos poderes públicos instituídos com uma série de pesquisadores, agentes públicos, empresas, pesquisadores, escritórios, agências nacionais e internacionais, que deverão ser o foco de diversas análises acadêmicas, nos próximos anos. Desse material, além dos excelentes mapeamentos e alguns novos exercícios de regionalização da metrópole Rio de Janeiro, destacam-se diagnósticos e propostas de estruturação de uma nova mentalidade sobre o poder nas metrópoles do país, a partir do Rio de Janeiro, pois esse ente federativo é inexistente como figura jurídica e de representação, mas que é um fato nos territórios de realização cotidiana de milhões de pessoas, diariamente. Nesse sentido, pensar cooperativamente a metrópole é mergulhar nas várias possibilidades de governança integrada e coparticipativa para que funções metropolitanas possam prover as redes regionais. Igualmente, pensar a metrópole brasileira hoje é retomar as discussões de 'vasos comunicantes' apresentadas pelo sistema jurídico-institucional marcado nas legislações brasileiras nos anos de 1960 a 1990. Regionalizar municípios e descentralizar a gestão se tornam processos complementares para a melhoria da qualidade da gestão pública dos espaços conurbados, pesquisando-se estratégias de gestão dos territórios na Geografia política.

\section{REFERÊNCIAS}

ALVES, Alaôr Caffé. Saneamento Básico. Concessões, Permissões e Convênios Públicos. Bauru: EDIPRO, 1998.

AMADOR, Elmo da Silva. Baia de Guanabara: ocupação histórica e avaliação ambiental. Rio de Janeiro: Editora Interciência,

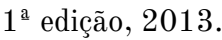

ARGIOLAS, G., CABRAS, S., DESSI, C., FLORIS, M. Building innovative models of territorial governance. Journal of Place Management and Development, 2(3), 178-210. 2009.

BELIK, Walter. O mundo não é um sistema de vasos comunicantes. Entrevista dada ao jornalista Andriolli Costa, do IHU Unisinos para o site Plataforma Social: caminhos para o desenvolvimento. Porto Alegre, 24/05/2014. Endereço eletrônico: http://plataformapoliticasocial.com.br/o-mundo-nao-e-um-sistema-de-vasos-comunicantes/. Acesso em: 12 ago 2017.

BONAVIDES, Paulo. A Regionalização Política do Brasil e a Nova República. Revista Brasileira de Estudos Políticos, 60/61, jan/jul. 1985, UFMG, BH, p. 195-232. 1985.

CASTRO, Ina Elias. Território do Estado: divisão ou fragmentação? Argumentos para um debate necessário. In: FONSECA, Antonio Angelo Martins da et al (org.) Estado, Território e a Dinâmica das Fronteiras: reflexões e novos desafios. Grupo de Pesquisa LESTE da UFBA, JM Gráfica e Editora Ltda, Salvador, 2013. p. 33-52.

Do imaginário tropical à política. A resposta da geografia brasileira à história da maldição. Revista eletrônica Geocritica, Barcelona, Espanha http://www.ub.es.geocrit, 2006. 
Territorialidade e institucionalidade das desigualdades sociais no Brasil. Potenciais de ruptura e de conservação da escala local. Revista Geousp, São Paulo, v. 18, p. 35-51, 2005.

; RODRIGUES, Juliana Nunes; RIBEIRO, Rafael Winter (orgs.). Espaços da democracia. Para a agenda da geografia política contemporânea. $1^{\text {a }}$ ed. Rio de Janeiro: Bertrand Brasil, 2013. v. 1. 260p.

DEL BALDO, Mara. Corporate Social Responsability and Corporate Governance in Italian SMEs: the experience of some 'Spirit Business', Spring Science+Business Media, LLC. 2006. Endereço eletrônico: http://works.bepress.com/mara_del_baldo/10. Acesso em: 04 jun. 2016.

DELGADO, Ma Ángeles; LÓPEZ, J. Damián y Otros: La recuperación del material científico de los gabinetes y laboratorios de Física y de Química de los institutos y su aplicación a la práctica docente en secundaria, en XXI Encuentros de Didáctica de las Ciencias Experimentales. Servicio editorial UPV, 2004, pp.361-380.

FERRÃO, João. O Ordenamento do Território como Política Pública. Lisboa, Fundação Calouste Gulbenkian, 2011.

FERRAZ, Sérgio. As regiões metropolitanas no direito brasileiro. Revista de Direito Público, nº37-38, p. 19-24, jun./jul.1976.

HERRERO FABREGAT, Clemente. Os símbolos da cidade do Rio de Janeiro vistos pelos jovens cariocas. Organizador SILVA, Augusto César Pinheiro da. Rio de Janeiro: Editora Gramma, 143p, 2017.

GARSON, Sol. Regiões metropolitanas: por que não cooperam? Letra Capital: Rio de Janeiro; Observatório das Metrópoles, PUC-MG, Belo Horizonte, 2009.

GRAU, Eros Roberto. A Ordem Econômica na Constituição de 1988: interpretação e crítica. 5ª Edição. rev. atual. São Paulo: Malheiros, 2000.

. Regiões Metropolitanas; regime jurídico. São Paulo: José Bushatsky, 1974

GUANABARA, Alcindo. A presidência Campos Sales. Brasília: Senado Federal, 2002.

INSTITUTO BRASILEIRO DE GEOGRAFIA E ESTATÍSTICA (IBGE). 2015. Dados atualizados sobre as populações totais dos RMs e RIDEs. Endereço eletrônico: http://agenciadenoticias.ibge.gov.br/2013-agencia-de-noticias/releases/9647ibge-divulga-as-estimativas-populacionais-dos-municipios-em-2015-atualizado-as-18-00h-do-dia-28-08-2015.html. Acesso: 12 jul. 2017.

INSTITUTO ESTADUAL DO AMBIENTE (INEA). 2010. Endereço eletrônico: http://200.20.53.3:8081/Portal/MegaDropDown/Regionais/BaixoParaibadoSul/index.htm\&lang=. Acesso: 12 . Jul. 2017.

INSTITUTO POLÍTICAS ALTERNATIVAS PARA O CONE SUL (PACS). Diagnóstico sobre a Baia de Sepetiba. http://www.pacs.org.br/files/2012/12/Ba\%C3\%ADa-de-Sepetiba-fronteira-do-desenvolvimentismo.pdf. Acesso em: 12 jul. 2017.

LENCIONI, Sandra. Urbanização difusa e a constituição de megarregiões. O caso de São Paulo-Rio de Janeiro. e-metropolis: Revista eletrônica de Estudos Urbanos e Regionais, v. Ano 6, p. 6-15, 2015.

MACHADO JÚNIOR, J. Teixeira. Regionalização ou Municipalização no Brasil? Revista Brasileira de Estudos Políticos, 63/64, jul.1986/jan.1987. UFMG, Belo Horizonte, p.171-183. 1986.

MINAYO, M.C.S.; HARTZ, Z.M.A.; BUSS, P.M. Qualidade de vida e saúde: um debate necessário. Rio de Janeiro: Ciência \& Saúde Coletiva, v.5, n.1, p.7-18, 2000.

MINISTÉRIO DE INTEGRAÇÃO NACIONAL. Endereço eletrônico: http://www.mi.gov.br/regioes_integradas_rides. Acesso em: 12 jul. 2017.

PACÍFICO, Alan Gustavo Fernandes. Transporte Aquaviário de Passageiros na Baía de Guanabara (RJ): monopólio e gestão das acessibilidades em uma perspectiva geográfica. Dissertação de Mestrado. PGE/PUC-Rio, 2013, 176p. 
PAULO, Bárbara de Oliveira. Sobre resistência e resignação: o exercício do poder político no combate à produção de corpos doentes. Dissertação de Mestrado. PGE/PUC-Rio, 2015, 218.

PEREIRA, Érico Felden et al. Revista brasileira de Educação Física. São Paulo: Esporte, v.26, n.2, p.241-50, abr./jun. 2012.

PLANO METROPOLITANO DE DESENVOLVIMENTO INTEGRADO DA GRANDE SÃO PAULO, Grupo Executivo da Grande São Paulo, GEGRAN, 1971.

Relatório de Propostas de cenários (FINAL). Projeto 'Modelar a Metrópole'. Produto 10. 2017. Rio de Janeiro. SEPLAG/Rio. Endereço eletrônico: http://www.modelarametropole.com.br/wpcontent/uploads/2017/07/PRODUTO_10_.pdf. Acesso em: 12 jul. 2017.

RODRIGUES, Juliana Nunes. Cooperação e Coesão para o Desenvolvimento? Uma reflexão sobre arranjos territoriais cooperativos no pacto federativo brasileiro. In: II Congresso Internacional Estado, Território e Desenvolvimento, 2015, Santiago de Compostela. II Congresso Internacional SETED-ANTE, 2015. v. 1. p. 1-16.

SECRETARIA DE PLANEJAMENTO E GESTÃO DO ESTADO DO RIO DE JANEIRO (SEPLAG). Endereço eletrônico: http://www.rj.gov.br/web/seplag/exibeconteudo?article-id=257671. Acesso em: 12 jul. 2017.

SILVA, Augusto César Pinheiro da. Uma Trajetória de Investigação de Geografia Política na Região Metropolitana do Rio de Janeiro. GEOgraphia (UFF), v. 18, p. 95-114, 2016.

Redefinindo a Paisagem do Rio de Janeiro: dilemas constantes sobre o espaço carioca.

Cadernos do Desenvolvimento Fluminense, v. 0, p. 57-73, 2015.

O território fluminense em questão: a re-significação da cidade e do estado do Rio de Janeiro após 30 anos de fusão. In: Agricultura, Desenvolvimento Regional e Transformações Socioespaciais, 2005, Rio de Janeiro. Agricultura, Desenvolvimento Regional e transformações Socioespaciais. Rio de Janeiro: CEPUERJ, 2005.

. Cooperativismo e Autonomia: pela transformação das práticas e dos objetivos associativistas no espaço rural brasileiro. Revista GeoUERJ, Rio de Janeiro, p. 72-96, 2002.

SISTEMA DE VASOS COMUNICANTES. Site do EBAH. Endereço eletrônico:

http://www.ebah.com.br/search?start=50\&q=vasos-comunicantes. Acesso em: 12 jul. 2017.

SLAWINSKI, Pedro Gonçalves da Rocha. Regiões Metropolitanas e Serviços Públicos de Interesse Comum. Revista de Dir. Proc. Geral, Rio de Janeiro, (60), 2006, p. 214-239.

SOUZA, Celina. Modernização do Estado e construção de capacidade burocrática para a implementação de políticas federalizadas. Revista de Administração Pública (Impresso), v. 51, p. 25-45, 2017.

Federalismo: Teorias e Conceitos Revisitados. BIB. Revista Brasileira de Informação Bibliográfica em Ciências Sociais, v. 65, p. 27-48, 2008.

. Federalismo, desenho constitucional e instituições federativas no Brasil pós-1988. Revista de Sociologia e Política, Curitiba, v. 24, n.24, p. 105-122, 2005.

TÁCITO, Caio. Saneamento básico - região metropolitana. Competência estadual. Boletim de Direito Administrativo, São Paulo, NDJ, v.6, p.453-457, 2002.

VALLE, Willian Andrion do. As implicações territoriais da pacificação de favelas: um estudo sobre a Unidade de Polícia Pacificadora na Mangueira. 2016. Dissertação de Mestrado. PPGG/FFP-UERJ, 2016, 174.

VIEIRA, MÁRCIO VIVEIROS. O Programa de Despoluição da Baía de Guanabara. Entraves institucionais e impactos territoriais na Região Metropolitana do Rio de Janeiro. Dissertação de Mestrado. PPGG/UFRJ, 2009, 101p.

VILlELA, SOUTO, Marcos Juruena. Parcerias Decorrentes do Programa Estadual de Desestatização. Revista de Dir. Proc. Geral. Rio de Janeiro, v.59, p.155/156, 2005. 